\title{
O corpo importa: corpos falantes e a produção discursiva do sexo
}

\author{
Camilla de Magalhães Gomes' (iD) 0000-0001-6993-7289 \\ 'Centro Universitário de Brasília, Brasília, DF, Brasil. 70790-075
}

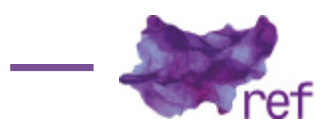
Resumo: Os estudos decoloniais nos mostram que a colonialidade tem por dicotomia fundamental a
divisão entre humanos e não humanos. Que processos, contudo, produzem ou preenchem essa
oposição? No presente artigo buscamos discutir o sexo como produção discursiva que faz parte dos
processos de distribuição de humanidade da colonialidade ocidental. Para isso, trabalha a noção de
corpos falantes, como modo de romper com a ideia do corpo como tela em branco, natureza a que
se imprime sentido por meio da cultura. Com isso, torna-se possível questionar o dimorfismo sexual e
pensar na ampliação dos modos pelos quais atribuímos a linguagem do sexo e, assim, reconstruirmos
a linguagem sobre os corpos para permitirmos mais, para podermos dizer que, apesar de só
conhecermos os corpos por meio da linguagem, esses sempre a excedem.

Palavras-chave: Sexo; linguagem; corpos; dimorfismo sexual; colonialidade.

The Body Matters: Speaking Bodies and the Discursive Production of Sex

Abstract: The decolonial studies show us that coloniality has as its fundamental dichotomy the division between humans and non-humans. What processes, however, produce or fill this opposition? This article seeks to discuss sex as a discursive production that is part of the processes of humanity distribution of western coloniality. In order to do so, it works with the notion of talking bodies, as a way to break with the idea of the body as a blank canvas, nature to which a sense is imprinted through culture. In this way, it becomes possible to question sexual dimorphism and to think of the magnification of the ways in which we attribute the language of sex and thus reconstruct language over bodies in order to allow more, so that we can say that although we only know the bodies through of language, they always exceed it. Keywords: Sex; Language; Bodies; Sexual dimorphism; Coloniality.

\section{Introdução}

Perguntar o que nos faz humanos talvez seja uma questão que perpassa muitas das áreas de conhecimento na perspectiva da colonialidade ocidental - filosofia, antropologia, direito, medicina, biologia. Em uma virada decolonial, talvez poderíamos dizer que esse perguntar é parte do projeto de dominação da colonialidade: como aponta María Lugones (2014), a modernidade colonial tem como dicotomia fundamental, como pensamento fundante, a divisão entre humanos e não humanos. Essa divisão, contudo, não faz apenas hierarquizar humanos e outros animais, não apenas serve a discursos e práticas de dominação entre aqueles e esses, dados por inferiores naquela dinâmica; ela também serve a hierarquizar humanos: humanos e menos humanos, humanos e não humanos. Ela promove, assim, processos de desumanização, processos esses que são o centro do colonialismo e da colonialidade que the sucede.

É com essa visão em mente que neste artigo se faz a presente questão: assumindo que os discursos sobre o sexo fazem parte do processo acima referido, como eles atuam nessa desumanização? Rompendo com a ideia de ser o sexo um elemento de natureza - da antiga forma de associar sexo e gênero com natureza e cultura -, o texto levanta a defesa de colocar 
lentes sobre o sexo, reivindicando que tal categoria não precisa ser parte apenas das ciências biológicas, cabendo também às ciências sociais, à filosofia e ao direito questionarem o que constitui e como se constitui a linguagem sobre o sexo, de que forma essa linguagem preenche a dicotomia fundante da colonialidade e de que forma é possível expandir os limites de referida linguagem como parte de uma prática performativa que contribua para a expansão dos limites do vivível e do possível do humano' (Camilla de MAGALHÃES GOMES, 2019b; 2019a).

A questão, então, é que não basta tomar o gênero como ponto de partida para questionar o sentido do humano. Colocar em questão conceitos como o gênero, mesmo que signifique muitas vezes entrar em terrenos difíceis, ainda representa uma problematização mais simples - ou mais fácil de se realizar - do que questionar conceitos como corpo e sexo. As reivindicações acerca da materialidade e da natureza dessas últimas duas categorias tornam o debate possivelmente mais árido ou, ainda, fazem com que tal debate seja preterido por se compreender fazer parte apenas do campo da biologia. Como, contudo, toda linguagem sobre corpos, o sexo pode e precisa ser objeto de nossas reflexões acerca do humano. E é nessa relação corpo e sexo que sigo.

\section{As linguagens sobre corpos e os corpos falantes que excedem a linguagem}

Já se tornou lugar comum sustentar que falar de gênero é falar de sexo. Ocorre que tem se tornado difícil, ou quase impossível, falar de sexo sem, ao mesmo tempo ou conjuntamente, falar sobre corpos. Falar sobre corpos é, em alguma instância, falar sobre corpos sexuados, ao mesmo tempo em que falar sobre sexo é falar sobre o corpo que "guarda" o sexo. Compreendermos o sexo depende de que tipo de modelo de corpo levamos em consideração, diz Anne Fausto-Sterling (2012, p. 78), e o contrário também me parece verdadeiro, portanto.

Para Raewyn Connell e Rebecca Pearse (2015), apesar de a abordagem feminista que vê os corpos como "tela em branco" - sendo, assim, construcionista - ter sido produtiva, ela enfrenta dificuldades, "visto que enfatiza o significante a ponto de o significado praticamente desaparecer" (p. 96), sendo o significado aqui o corpo. Connell e Pearse (2015) acreditam que nem é possível sustentar a dicotomia dos corpos nem sustentar o modelo da "máquina ou da tela em branco" (p. 101). Afinal, como temos acesso a essa matéria dos corpos? Como ela é usada ou recusada no discurso de gênero? Um tal corpo natural, corpo como tela em branco, existe? Para dizer que o corpo é essa tela em branco, eu precisaria ter acesso a ele como tal e conhecê-lo neutro, livre de significado, livre de linguagem. O que quero sustentar aqui, na direção oposta, é que só temos acesso aos corpos como corpos sexuados ${ }^{2}$ e que o processo de atribuição do sexo e a criação da matriz ou ideal de gênero é processo discursivo que ganha força no marco da colonialidade.

A defesa de que não há esse corpo neutro pode ser encontrada em vasta literatura. Berenice Bento (2006), por exemplo, enxerga três tendências explicativas nos estudos de gênero: a universal, a relacional e a plural, sendo que cada uma dessas tendências apresenta "teses próprias sobre as relações entre os gêneros, a sexualidade e o corpo" (p. 69). A primeira tendência é a da universalidade da subordinação feminina, representada, segundo a autora, pela tese de Simone de Beauvoir (2009) sobre o "tornar-se mulher" (BENTO, 2006, p. 70). Bento considera que tal percepção essencializa mesmo desnaturalizando (o que seriam duas estratégias não necessariamente equivalentes), uma vez que se sustenta na identificação de dois corpos diferentes, fazendo do corpo-sexo matéria fixa, dividida em duas formas que em si são folha em branco aguardando "o carimbo da cultura", com o gênero dando forma e significado, num movimento que essencializa identidades, com a mulher como o outro absoluto do homem - sujeito universal (BENTO, 2006, p. 71). Bento (2006) identifica, na sequência, a concepção relacional, orientada por "pressupostos teóricos como a concepção de poder e a dimensão relacional para a construção das identidades de gênero". Inclui aqui a tese de Joan Scott e a crítica de que esta, ao usar "diferenças percebidas entre os sexos" (p. 75), deixa intacto e inquestionado o dimorfismo sexual, gerando uma contradição entre o conceito e o objetivo de sua teoria, como comentei acima (BENTO, 2006, p. 76-78). Uma das principais críticas que Bento faz à tendência relacional é a de que ela, também sustentada na diferença sexual, constitui-se quase sempre em um "relacional de dois" (p. 77), concluindo que:

\footnotetext{
${ }^{1}$ Em meu trabalho de tese de doutoramento, coloquei a proposta de refletir sobre as formações em torno do humano no Direito, em especial como os conceitos de dignidade da pessoa humana e de povo tomam o que é ser humano como parte de sua constituição. Para isso, o primeiro passo consistiu em traçar os marcos teóricos a partir dos quais discutiria o humano no trabalho, o que dependeu de articular quatro categorias: corpo, raça, sexo e gênero. A ideia é que essas categorias, como categorias de análise teórica, sejam usadas como substrato para a análise dos institutos jurídicos e não o contrário: no lugar de usar o direito para pensar como trabalhar com raça e gênero, por exemplo, proponho que os saberes sobre essas quatro categorias articuladas forneçam material para trabalhar o Direito. Assim, aqui neste artigo, quando me refiro ao conceito de humano, falo de processos - filosóficos, políticos, linguísticos e jurídicos de atribuição ou de definição de humanidade. Pensando assim, com a filosofia e com a teoria da performatividade, junto aos estudos decoloniais, falo de processos de atribuição de humanidade.

${ }^{2} \mathrm{Na}$ linha que tenho seguido, gênero, sexo e raça trabalham juntos nestas formas de conhecermos os corpos. $\mathrm{A}$ separação que faço ao falar somente de sexo, excluindo a raça, é apenas para os fins deste artigo.
} 
sexualidade, gênero e subjetividade foram, na segunda onda, informados pela binariedade e pelo heterossexismo (BENTO, 2006, p. 78).

Ao desenvolver as características ou momentos da tendência plural, Bento fala dos estudos queer e aponta alguns pressupostos em comum destes: "a sexualidade como um dispositivo; o caráter performativo das identidades de gênero; o alcance subversivo das performances e das sexualidades fora das normas de gênero; o corpo como um biopoder, fabricado por tecnologias precisas" (p. 81). E por que as políticas queer podem ser identificadas por sair de um relacional de dois para uma concepção plural? Essa política é baseada na instabilidade das identidades (BENTO, 2006, p. 82) e, talvez por isso, tal tendência tenha sofrido e vem sofrendo tanta resistência: ao introduzir elementos que desestabilizam as identidades coletivas - tomadas em perspectivas anteriores como essenciais à política -, a teoria e política queer promove uma desestabilização da institucionalização (do gênero) como processo em que são mantidos "benefícios materiais obtidos por meio da reprodução das categorias rígidas e transparentes" (BENTO, 2006, p. 84). E essa desestabilização começa pela compreensão do que seja corpo e sexo.

Estou aqui partindo da compreensão de que só acessamos o mundo por meio da linguagem. Constituímo-nos como sujeitos por meio da linguagem, ao mesmo tempo em que a constituímos. E se assim é - e parece-me que sim - não há corpo nem sexo como dado natural. $E$, assim sendo, também corpo e sexo podem ser submetidos a leituras para além de uma "descrição da natureza", recebendo uma leitura, portanto, performativa. Desse modo, assim como na crítica feita por Judith Butler à teoria de John Austin (1975) sobre os atos performativos, ao falar sobre corpo e sexo como produções discursivas, não estou adotando um ponto de vista construcionista, em que um "eu" imprime significado a um corpo, sendo esse eu e esse corpo anteriores ao processo de significação. Quem é esse "eu" que decide pela obra, que constrói o corpo? O fato é que ele não existe, não como um a priori do processo de atribuição de sentido: ele já nasce no processo de atribuição de sentido, ao mesmo tempo em que participa do processo. A questão deixa de ser como o sujeito se constrói, ou como se colocam numa relação causa-efeito construtor e constructo, ou, ainda, como encontrar a origem do processo de construção. O ponto passa a ser quais os saberes que, hegemonicamente, conduzem e circundam esse processo e como esses saberes são, em realidade, eles mesmos, sedimentação de práticas sociais (Judith BUTLER, 2000, p. 19) e, assim sendo, podem ser submetidos a reinterpretações e reinscrições subversivas para permitir outras ou novas ou mais formas de "ser". E, também, que os corpos são mais do que essas linguagens e saberes hegemônicos permitem.

E se não estou tratando de um corpo como tela em branco, de que corpo falo? No lugar desta concepção, uso a ideia de corpos falantes, de Shoshana Felman (2003). A autora, ao tratar dos atos de fala performativos e retomar Austin, diz que os corpos cometem atos de linguagem que sempre excedem sua intenção e nisso vê o poder performativo da linguagem (p. IX). É possível mesmo dizer que, para a autora, os atos dos corpos falantes são, em algum sentido, desconhecidos e que sempre "dizem algo que não pretendem" (BUTLER, 1997, p. 10). O ato de fala dos corpos falantes sempre produz sentidos diversos do que foi intencionado. Austin (1975) disse que todo ato de fala é uma locução performativa na medida em que é sempre um fazer, o ato de dizer algo. Pensando desse modo, é possível que Felman (2003) então pegue esse ponto e o estenda: é um ato corporal e, como tal, o ato de fala dos corpos falantes sempre produz sentidos diversos daquilo que foi intencionado e a relação entre fala e corpo é sempre uma relação escandalosa, "uma relação consistente ao mesmo tempo de incongruência e inseparabilidade [...] o escândalo consiste no fato de que o ato não pode saber o que está fazendo" (FELMAN, 2003, p. 96) e sempre, portanto, diz algo - mais ou diferente - que não pretendia dizer sendo corpo e fala inseparáveis, ainda que não redutíveis um ao outro. Essas posições são interessantes para deslocar ou mesmo abandonar a noção de centro e de controle. Atos de fala estão sempre fora de nosso controle. Uma enunciação performativa que fuja à intenção do falante mesmo assim poderá produzir efeitos, poderá ter força e por isso é preciso pensar na responsabilidade daquele que profere o discurso, mas mais ainda daquele que dele se utiliza ou, para usar o termo comum a essa área, aquele que o cita, para além da intenção e do contexto "originais" (BUTLER, 1997).

Não se trata, então, de dizer que o discurso ou a linguagem formam os sujeitos como uma relação de originalidade, como se os sujeitos apenas viessem a ser quando produzidos pela linguagem (BUTLER, 1993). Nossas descrições sobre os corpos são sempre igualmente formativas desses corpos. Nossas definições sobre sexo, gênero e humano não são puras descrições. Mesmo porque a divisão entre constatativos e performativos também é uma atividade de fracasso e a performatividade, do ponto de vista filosófico, também é característica do constatativo, também está presente no constatativo. Em alguma medida, não há pura descrição. Ao mesmo tempo, contudo, o corpo excede, diz mais, produz linguagem, há sempre "uma dimensão da vida corporal que não pode ser completamente representada" (BUTLER, 2004, p. 198-199). Há sempre um excesso e esse excesso, esse escândalo, esse componente corporal da linguagem é o poder performativo da linguagem (FELMAN, 2003) e sua possibilidade de subversão. O ato de fala dos corpos falantes sempre produz sentidos diversos daquilo que foi intencionado e a relação entre fala e corpo é 
uma relação escandalosa. Assim, corpo e fala são inseparáveis, como corpo e mente igualmente inseparáveis, e se misturam. E é assim que podemos repensar o que dizemos sobre sexo. Desse modo, minha análise sobre a relação entre sexo e gênero não terá por base essa dicotomia entre natureza/cultura. Essa análise não trará resposta sobre o que significa cada um desses conceitos, talvez porque não haja nada na noção moderna de sexo que possa ser afirmado como observação (Thomas LAQUEUR, 2001).

\subsection{Corpos sexuados: questionando o dimorfismo sexual}

Não tem sido tarefa fácil questionar conceitos como corpo e sexo e a dificuldade começa justamente em colocá-los como conceitos, como produções (e produtores) do discurso. Os obstáculos talvez estejam relacionados mesmo àquela forma rígida de oposição natureza/cultura, em que corpo e sexo corresponderiam a dados do primeiro campo e gênero ao segundo. Essa forma, que é a que também separa corpo e mente, também inspirou o feminismo, que na separação sexo/ gênero recusou falar do corpo ou o excluiu da teorização. Esse, natureza, ou era esquecido como modo de se evitar um determinismo biológico, ou era exaltado como lugar de essência do feminino. Mas, ao recusar o corpo, o feminismo deixa-o nas mãos das produções discursivas, deixa-os nas mãos da biologia produzida hegemonicamente. Desfazer essas separações, ou melhor, aproximálas, é necessário para se reconhecer que campos como o da biologia/medicina não são produtores de mera descrição, mas áreas de conhecimento que produzem significado sobre os corpos e sua humanidade.

É assim que Berenice Bento e Judith Butler leem a teoria de Simone de Beauvoir, como devedora dessas dicotomias que, de algum modo, ao mesmo tempo em que produziu avanços significativos na política e teoria feministas, produziu essencializações sobre "mulher", "corpo", "feminino", "desejo", "sexo". Na teoria da autora francesa, o homem é o sujeito, o sujeito abstrato, não corpo. A mulher é o outro do homem, corpo a que se dá sentido pelo desejo masculino. Tal teoria pressupõe dois corpos dimorficamente diversos em que se imprimem os significados do masculino e feminino. E é essa pressuposição que precisa e pode ser colocada em questão: a leitura dos corpos como "naturalmente" dimórficos.

Em Sex and Gender in Simone de Beauvoir's Second Sex, Butler (1986) aponta que Beauvoir não adota uma separação entre corpo e significado. Alguns anos depois, em Gender Trouble, essa concepção se altera e ela se corrige, pontuando que a autora francesa - assim como Sartre - adota o corpo como uma "facticidade muda, antecipadora de algum significado que só pode ser atribuído por uma consciência transcendental, compreendida, em termos cartesianos, como radicalmente imaterial" (BUTLER, 2003, p. 186). Nessa perspectiva estruturalista, mente/corpo corresponde à cultura/natureza.

Uma outra crítica que se pode fazer a respeito da oposição mente/corpo como correspondente à cultura/natureza é a circunstância de que ela cria um referencial fixo no corpo "natural e pré-linguístico" e essa fixidez estabelece os próprios limites - rígidos e, portanto, não maleáveis - para uma construção alternativa, subversiva, expansiva do sexo e do gênero, para uma, pequena que seja, reconfiguração do binário. Mas o corpo é, na verdade, "fundamentalmente plástico, maleável e manipulável" (BENTO, 2006, p. 94), ao mesmo tempo em que está já carregado de significados produzidos por meio de "convenções históricas" dos discursos da matriz branca cis-hetero conforme que constroem dimorficamente "corpos sexuados inteligíveis" (BENTO, 2006, p. 88). No lugar de um agente que constrói o gênero imprimindo cultura à natureza, mente ao corpo, entra em cena o agente que, nascido e inserido já em determinados discursos que não escolheu para si, toma esses discursos e, em sua agência, performa o gênero, repetindo a norma ou reinscrevendo-a subversivamente, como pretendo demonstrar. Por isso importa tanto desfazer a rigidez das dicotomias aqui indicadas. Assim, essa forma dicotômica de pensar não mais se sustenta: seja pelas inúmeras teorias que implodiram o sujeito seja pelo fato de que as "máquinas do final do século XX tornaram completamente ambígua a diferença entre o natural e o artificial, entre a mente e o corpo, entre aquilo que se autocria e aquilo que é externamente criado" (Donna HARAWAY, 2009, p. 43).

A teoria decolonial, o feminismo, o movimento negro, os movimentos LGBTTQIA e todo o conhecimento produzido por aqueles que são o outro feito apenas corpo sem razão nos mostraram que essa razão, esse sujeito, essa mente descorporificada é a reprodução de um padrão hegemônico comumente identificado com o homem branco, cissexual, heteroconforme, classe média [...] e fundado numa relação de dominação: razão que domina o corpo, cultura que domina a natureza, humanos que dominam não humanos, em relações de corporeidades racializadas e generificadas. Nesta onda, diferente do que se pensa, o corpo não é objeto ahistórico, matéria pura a que a mente confere sentido. Ele é uma história, tem histórias, ganha seus significados dentro da história (FAUSTO-STERLING, 2012, p. 79). Ele é materialidade, mas ao mesmo tempo ganha materialidade por meio de discursos que reconhecem ou dão significado para alguns, enquanto negam significados a outros, excluídos. O que não significa que esses outros 
não existam, mas que existem de modo precário, vulnerável, não dito, na margem, em um limite de negativa de humanidade constante.

A normatividade de sexo-gênero cria a sua margem, o seu abjeto, constrói um ideal a partir da rejeição de um modo de ser, de um corpo rejeitado, de formas múltiplas que não se adéquam ao modelo da heteronorma. E se, como falei no início, as linguagens que imprimimos sobre os corpos fazem parte da forma como entendemos e construímos as noções sobre humanidade, tal normatividade binária (masculino-feminino, homem-mulher, pênis-vagina, macho-fêmea) contribui - ou tem significativo papel - nos processos de desumanização. Quando os estudos decoloniais nos mostram que a oposição humano-não humano é a dicotomia que sustenta a colonialidade, ela nos ajuda a pensar como determinadas produções discursivas preenchem essa dicotomia, criando processos próprios de hierarquização de humanos, criando seus próprios fora da norma.

Neste contexto, chegamos ao sexo como produção discursiva, como linguagem que faz parte dos processos de atribuição de humanidade - ou processos de desumanização. Aqui, contudo, apesar de entender que lemos o corpo a partir dos discursos do sexo, posso preliminarmente e artificialmente separar os dois para fim de análise. Os corpos existem em sua multiplicidade, livres, dependentes, diferentes, mutáveis, plásticos. Mas os discursos hegemônicos que lhes conferem sentido - e, portanto, criam corpos ao mesmo tempo em que os "descrevem", em um movimento performativo - só concebem dois corpos sexuados: feminino e masculino. Uma das linguagens atuais responsáveis por nomear os corpos como corpos-sexuados é a linguagem médico-científica. Sua ideia de que os corpos possuem duas formas distintas é uma produção da ciência do século $\mathrm{XIX}$ : de um isomorfismo que concebia o feminino como continuação do masculino ou como um homem invertido (LAQUEUR, 2001), passa-se à criação de corpos sexuados que possuiriam "naturalmente" duas formas diversas e a ideia de que esse corpo-sexuado é um dado originário. Até o século XIX, a noção de um sexo biológico como conhecemos não existia (BENTO, 2006, p. 119): os dois sexos foram inventados como um "novo fundamento para o gênero", como base do gênero, ou seja, os corpos passam a ser dados originários que justificam, a partir da natureza, as diferenças e, em especial, as desigualdades entre homens e mulheres (BENTO, 2006, p. 115).

O sexo faz parte, então, de um discurso, aparece como uma operação performativa que produz dois "tipos" de corpos ou dois sentidos sobre os corpos. Aqui, talvez, os termos criar, produzir e operação ganham ainda mais força performativa do que se imagina. Anne Fausto-Sterling (2000; 2012), em Sexing the Body: Gender Politics and the Construction of Sexuality e Sex/gender: biology in a social world, nos conta como corpos de bebês intersexuais são modificados após o nascimento para que se adéquem a uma das formas do dimorfismo sexual, por meio de cirurgias com finalidade, na maioria das vezes, cosméticas. Trata-se não de uma modificação corporal com finalidade de melhora das condições de saúde do bebê ou necessidade de sobrevivência. A sobrevivência que está em jogo é a do próprio dimorfismo: corpos intersexuais existem, são realidade e mostram que as conformações entre os modelos de sexo - como "modelos cromossômicos, hormonais, gonadais e anatômicos do que se espera, em termos socioculturais e médico-científicos, de corpos masculinos e femininos" (PIRES, 2014, p. 5) - são bem mais variáveis que as duas linhas únicas criadas pelo dimorfismo.

Falar sobre pessoas intersexuais pode ter dois significados. Um primeiro de, dentro deste trabalho, falar de corpos que existem e aos quais é negada humanidade por não se conformarem com a matriz de inteligibilidade, ou, ainda, aos quais é negada humanidade até que a ela se conforme. Ao mesmo tempo, vale também para dizer que a biologia importa, que retomar os discursos da biologia para permitir mais vida importa. Com isso, quero dizer que separar "natureza" de "biologia" é fundamental. Afinal, como diz Hari Kunzru (2009), "em conversas, quando as pessoas descrevem algo como sendo 'natural', elas estão dizendo que 'é assim que o mundo é, não podemos mudá-lo'” (p. 25). Quando falamos, contudo, de biologia, não falamos de natureza, mas de discursos produzidos a respeito desta e que não são somente descrições, mas atos de fala performativos que constroem o sentido dessa suposta natureza - aqui, da natureza dos corpos.

Pires (2014), ao acompanhar um grupo de médicos no "atendimento e encaminhamento de pacientes com genitália externa ambígua" (p. 1), identifica o que Paula Sandrine Machado (2008a) chamou de "gerenciamento sociomédico": ao lidar com bebês intersexuais, o discurso médico-científico, apesar de se assentar em códigos médicos, utiliza continuamente concepções sociais para "decidir" o sexo a ser atribuído aos bebês. A questão intersexual é identificada pelos médicos como um 'problema' que requer 'intervenção': "É papel do profissional de saúde ajustar aquela ausência ou ambiguidade para modelos corporais que podem ser assimilados clínica e socialmente" (PIRES, 2014, p. 2). Para os médicos, a situação do corpo do bebê intersexual é uma emergência, justificada pela alegação de que a ausência de sentido ao corpo, ou melhor, a ausência de adequação aos sentidos disponíveis criados pelo discurso médico trará angústia e sofrimento psicológico para a criança e a família. Em sua narrativa, Pires conta que o que mais parecia angustiar os médicos não era a saúde do bebê, mas a "questão" do sexo (PIRES, 2014, p. 14). A angústia revela que, para estes, o "problema está no indivíduo, e não nas normas de 
gênero" (BENTO, 2006, p. 132) e, com essa inversão operada, a escolha é a de modificar o primeiro para adequá-lo ao segundo, com base em práticas em si generificadas (PIRES, 2014, p. 6).

O que se encontra aí é uma atuação com base em um conceito ou ideia de sexo que é, em si, reflexo ou consubstanciação de ideias de gênero. As teorias médicas sobre o sexo - tanto as do sexo único quanto as do sexo dimórfico - já estão impregnadas da linguagem do gênero e não se encontra nenhuma descoberta que tenha originado "o modelo de dois sexos, precisamente pelas mesmas razões que as descobertas da Renascença não originaram o modelo de sexo único": Thomas Laqueur (2001) defende que não há exame empírico capaz de revelar uma natureza da diferença sexual (p. 193). Não é de se surpreender, então, que na "resolução" dos casos de intersexualidade, os critérios apontados para a escolha do sexo resultado da "correção" não sejam estáveis ou unânimes. Primeiro porque, antes de qualquer critério físico, aparece o que já apontamos: "o bem-estar psicossocial do paciente e da família é apontado como norte em qualquer fala" (PIRES, 2014, p. 11). Depois aparecem os motivos funcionais, reprodutivos e sexuais: em alguns casos - especialmente aqueles em que se define o sexo feminino - a função reprodutiva é o critério. Em outros - especialmente os casos de definição de sexo masculino - um órgão sexual funcional é o critério. Qualquer semelhança com noções de papéis de gênero numa "arena reprodutiva" (CONNEL; PEARSE, 2015) não é mesmo nenhuma coincidência.

Os corpos intersexuais existem e "colocam em perigo" a sobrevivência do sexo dimórfico. Como aponta a literatura, é justamente a atuação das organizações de pessoas intersexuais que faz com que a hegemonia e a certeza do saber médico na solução cirurgia-hormonização sejam abaladas e submetidas à crítica e revisão: a mudança na forma de tratamento da questão da intersexualidade é resultado da ałuação das organizações de intersexuais que passaram a pleitear informações mais claras e adequadas e direitos (Anibal Ribeiro GUIMARÃES JR, 2014, p. 26; FAUSTOSTERLING, 2000, p. 79). Enquanto isso, normas médicas procuram criar termos "técnicos" para um público"restrito" para frear a crítica "como uma reação à visibilidade do movimento político intersex" (MACHADO, 2008b, p. 110-1 1 1), como quem tenta diminuir "as possibilidades de fissuras trazidas pela materialidade da ambiguidade nos corpos intersexuais" (PIRES, 2014, p. 7).

Sob o sexo dimórfico, nega-se sentido a esses corpos e, assim, nega-se humanidade às pessoas intersexuais. Ou melhor, dentro dos discursos médico e jurídico, somente se confere significado se e quando submetidos a procedimentos cirúrgicos e reposições hormonais que os molde na matriz inteligível. Biologia, medicina e direito funcionam na limitação do possível dos corpos, da vida e do humano e, sob a justificativa da angústia - angústia que, nos conta Pires (2014), é antes de tudo dos próprios médicos, incapazes de lidar com o corpo humano que não se encaixa em seu campo de saber (p. 4) - e do sofrimento psicológico por não viverem o sexo dimórfico, mutilam corpos para continuadamente performar a ficção do dimorfismo. A imposição de adequar-se a um dos dois gêneros (sexos) cognoscíveis socialmente é real, pois, como diz Butler (2003), "a marca do gênero parece 'qualificar' os corpos como corpos humanos" (p. 162); o bebê se humaniza no momento em que a pergunta 'menino ou menina?' é respondida. As imagens corporais que não se encaixam na norma de inteligibilidade ficam fora do humano.

O que se desenha com essas considerações é a afirmação de que o sexo é também uma produção discursiva e que sua atribuição dimórfica é arbitrária. O sexo é a categoria que, por meio de linguagem, dá ao corpo ou, mais especificamente, a um conjunto de características físicas "sentido e unificação sociais". "Como discursivo e perceptivo, o 'sexo' denota um regime epistemológico historicamente contingente, uma linguagem que forma a percepção, modelando à força as inter-relações pelas quais os corpos físicos são percebidos" (BUTLER, 2003, p. 166). É a categoria do sexo que define os corpos possíveis e inteligíveis e, ao mesmo tempo, esconde o caráter arbitrário dessa operação ao ser apresentado como em si uma categoria natural e é por esse motivo que ela merece uma desnaturalização.

A arbitrariedade na construção dos corpos sexuados não está só na junção dos atributos sob a categoria do sexo, mas também na própria discriminação dos atributos físicos que o constituem (BUTLER, 2003, p. 166). Fragmenta-se o corpo em 4 partes ou níveis - cromossomos, genitália, gônadas e hormônios - e daí reduz-se a experiência do sexo a esse conjunto de partes, ao mesmo tempo em que elas são reduzidas a uma função sexuada. O momento de dizer "É uma menina", a partir de exames como uma ecografia, constitui não uma descrição, mas um ato performativo: a fala cria o corpo. Ou, mais que isso, uma fala com efeitos protéticos que faz corpos (Beatriz PRECIADO, 2014) e, então, é possível dizer que, no nível discursivo, não mais as pessoas intersexuais são as únicas em que uma operação se produz: "os corpos já nascem operados" 3 e sua materialidade nunca é conhecida livre, pura ou neutra mas, pelo contrário, está já condicionada desde o início a regimes discursivos de poder e é nisso que se encontra o sexo, não como algo que o sujeito "tem" nem como descrição dos corpos: o sexo é o regime de poder que torna os corpos inteligíveis (BENTO, 2006, p. 89).

${ }^{3}$ Com isso não pretendo de nenhum modo igualar a violência a que são submetidas as pessoas intersexuais por não se adequarem à norma, apenas indicar que o processo de atribuição de sexo é sempre isso: atribuição e, portanto, passível de arbitrariedade. 
Fausto-Sterling, após apresentar os diversos critérios de que lançam mão os médicos para definir o sexo da criança intersexual, diz que o conhecimento científico pode ser usado "para nos ajudar a tomar a decisão, mas apenas nossas crenças sobre gênero - não a ciência - podem definir o nosso sexo. Além disso, nossas crenças sobre gênero afetam o tipo de conhecimento que os cientistas produzem sobre o sexo" (FAUSTO-STERLING, 2000, p. 3). É o mesmo que Pires nos mostrou e que Laqueur sustenta. Apesar de recorrer a códigos-médicos, os profissionais continuamente usam concepções sociais de gênero para tomar a "decisão" sobre o sexo e, mais do que isso, a própria teoria sobre o sexo e a diferença sexual em que se fundam é um efeito de ideias de e sobre o gênero. Durante sua pesquisa, por exemplo, Pires (2014) nos conta que um dos médicos do caso que acompanhava, após a decisão de designar o sexo feminino a um bebê intersexual e como parte disso pedir que a mãe o levasse às consultas de roupa rosa, confessou que "não adiantava de nada a decisão médica de designar para o sexo feminino se a família não reforçasse este sexo social cotidianamente" (PIRES, 2014, p. 12).

Assim, não só é revelado o caráter artificial e discursivo do sexo, como também se percebe que sua inscrição nos corpos depende do gênero. A questão talvez seja que a "intersexualidade aparece como um elemento desestabilizador" que desloca os corpos do que deles se espera a partir dos "modelos cromossômicos, hormonais, gonadais e anatômicos" (PIRES, 2014, p. 5) que os separa em masculinos e femininos e revela a arbitrariedade do processo de atribuição e sua característica performativa. Nesse deslocamento, a intersexualidade revela a artificialidade do sexo, revela seu caráter performativo no lugar da propagandeada descrição neutra da ciência de moldes iluministas.

E se a experiência intersexual nos mostra que a atribuição é arbitrária, de outro lado, a experiência trans e travesti nos mostra que a arbitrariedade existe mesmo sem sua produção por meio de uma cirurgia: a atribuição de um nome ao corpo no nascimento não fala com a subjetividade e a identidade de gênero, não diz tudo sobre o sujeito que se forma. Mais uma vez, nos deparamos com a artificialidade do dimorfismo que pretende, com seus dois nomes, uma suposta descrição da humanidade que se mostra, contudo, um performativo disfarçado de constatativo. Ao levantar essas questões e falar da identidade de gênero de pessoas trans e travestis, não quero sustentar uma "realidade" psicológica, ou um sexo psicológico diverso do sexo biológico como explicação para a transexualidade. Para Preciado (2014), por exemplo, nenhum dos dois tipos de critérios são naturais e tanto os gêneros trans quanto os cis são "estatutos de gênero tecnicamente produzidos" (p. 93). Assim sigo, mesmo porque não estou realizando nenhuma teoria explicativa sobre a verdade do corpo ou do sexo. Ademais, advogar a existência de um sexo psicológico é retomar a dicotomia corpo e mente como campos rigidamente separados, é pleitear um "interno" apenas revelado no "externo" do corpo modificado ou modificável. Assim fazendo, retomaria um essencialismo, não mais apoiado na natureza do corpo, mas em uma natureza psicológica, uma verdade interna ou um interno inato do sujeito, posições das quais quero me afastar. Ainda que as questões de inter e transexuais em relação à atuação médica sejam diferentes, há pontos de encontro: primeiro, que "ambos desafiam o princípio de que um dimorfismo natural deveria ser estabelecido ou mantido a todo custo"; depois, que para ambos o gênero é uma questão a ser libertada de designações impositivas. E é nesse ponto que elas se encontram com a teoria performativa do gênero (BUTLER, 2004, p. 6-7).

\section{0 corpo importa}

Se, contudo, encerro essa narrativa aqui, um erro será fatal. Corpos cissexuais continuarão neutros e não será difícil dizer que, portanto, as histórias e experiências de pessoas trans e intersexuais são acidentes, desvios de uma normalidade, como se corpos cis fossem um lugar de pureza, ausência de incrementos, operações, cirurgias, hormonizações. Como se, ainda que eu possa considerar arbitrário o processo de atribuição do sexo, nos casos em que esse processo produz corpos cis, o "acerto" traduzisse uma espécie de "encaixe perfeito" do conceito em um corpo que dispensa modificações. Seria difícil, se pensasse assim e parasse aqui, abandonar o corpo cis como modelo, padrão ou referência de normalidade. E isso é justamente o contrário do que pretendo. O processo de atribuição do sexo não termina nem com a ecografia nem com o registro civil. E o processo de transformação do corpo e construção de significado não está nem apenas em cirurgias de designação (no caso de pessoas intersexuais) ou redesignação (no caso de transexuais) do sexo e nem somente em atos corporais e estilísticos de performance de gênero. Processos médicos, cirúrgicos, hormonizações, uso de medicamentos ou alterações corporais são diária e comumente também adotados por indivíduos cis para significar, incrementar ou viver seus corpos sexuados (PRECIADO, 2014).

O corpo é corpo tecnológico, é corpo ciborgue, corpo protético. Não só o corpo é ciborgue, mas defender o ciborgue como manifesto, como faz Haraway (2009), é defender a confusão: "com o ciborgue, a natureza e a cultura são reestruturadas: uma não pode mais ser o objeto de apropriação pela outra" (p. 39). O corpo é natureza e cultura, sempre modificado e modificável. 
Quando disse que não acessamos o corpo tela em branco, neutro, puro, falei de como ele já nos vem inserido na linguagem do sexo. E essa linguagem é, entre outras, a linguagem farmacêutica, tecnológica, médica. Com isso, tenho que ressaltar que não estou equivalendo em grau de violência ou de limitação e determinação de possibilidades de vida as realidades de pessoas trans, cis ou intersexuais. Mesmo porque, nessa linguagem farmacopolítica, modificações corporais que signifiquem incrementar o sexo designado no nascimento ou aumentar a visibilidade de sinais de gênero correspondentes ao sexo designado no nascimento são valoradas e permitidas de modo diverso daquelas alterações ou desejos de pessoas travestis, trans ou intersexuais (PRECIADO, 2014).

Com estas linhas, quero apenas indicar que não há - aqui entre esses corpos - uma distinção sobre corpos reais e corpos modificados, puros/tecnológicos, neutros/hormonizados ou qualquer outra forma de oposição que se queria introduzir. O corpo é situação, ao mesmo tempo, um locus de interpretações culturais, "uma realidade material que já foi localizada e definida dentro de um contexto social" e a situação de ter de tomar e interpretar esse conjunto de interpretações recebidas (BUTLER, 1986). O corpo é performatividade, como um campo de possibilidades interpretativas e se o lemos como uma "situação cultural" e se essa situação é a de corpos protéticos e tecnológicos, torna-se difícil sustentar o "natural" do corpo e do sexo.

Isso não quer dizer que o corpo seja todo linguagem, ou que não haja espaço não discursivo sobre ele. Retomando o que disse acima, o corpo sempre excede o que diz e o que sobre ele é dito, o sentido que lhe é atribuído. O corpo falante é escandaloso e não só ele excede o ato performativo que lhe confere sentido, esse de atribuição do sexo, como também excede os significados que se dá a si mesmo, pelos e nos atos que performa. Com isso, quero dizer que os atos corporais são capazes de repetir ou inscrever novos sentidos, novas linguagens. Isso significa que os atos corporais dos indivíduos que estão fora da norma podem reinaugurar a cadeia histórica dos sentidos dados aos corpos. Para que isso aconteça, no entanto, essas experiências devem ser vivíveis, devem ser permitidas, devem ganhar possibilidade, o que implica mudar as epistemologias de produção de normas sobre os corpos.

Butler (1987) sustenta que só conhecemos os corpos sexuados, generificados. Como "condição de acesso ao mundo" (p. 130), o corpo é corpo na linguagem, na linguagem do gênero. Como o corpo natural não é conhecido ou conhecível, toda experiência é uma experiência generificada e toda vida do corpo é, assim, conhecida e realizada por meio do gênero. Para ela, então, o "tornar-se" de Beauvoir precisa ser relido, porque ele não pode implicar um movimento de uma realidade/liberdade descorporificada para uma corporificação cultural. O movimento, diz Butler (1987), do sexo para o gênero, é interno à vida corporificada (de um tipo de corporificação para outro). "Que uma pessoa não nasce, mas se torna uma mulher não implica que esse tornarse indica um caminho de uma liberdade descorporificada para uma corporificação cultural". O sujeito é, então, de início, o corpo "e só depois se torna seu gênero". Não haveria, assim, experiência do corpo fora do gênero (BUTLER, 1987, p. 131).

Se não há conhecimento fora do gênero - porque não há conhecimento fora da linguagem -, é urgente ressignificar os discursos sobre este, mas mais do que ressignificar os discursos sobre o gênero, fazê-lo também a respeito do corpo e do sexo. A posição de Butler parece realizar duas operações: a primeira, a de assumir que todas fazemos gênero. ${ }^{4}$ Ainda que esse fazer gênero seja extremamente variável e nem sempre signifique a criação de estruturas hierarquizadas de relação, parece-me possível dizer que fazemos gênero como atribuição de significados a corpos, reprodução e relações.

Há uma outra operação aqui que é quase uma junção das categorias sexo e gênero em uma só. Não creio que seja possível ou mesmo seguro realizar essa junção, substituindo, por exemplo, as duas pelo uso apenas do gênero. Na realidade, o que se faz aqui - e creio que seja também o que faz Butler, num contexto geral de sua literatura -, é uma aproximação que quer desestabilizar a dicotomia sexo/gênero como dicotomia natureza/cultura. Perder o sexo como categoria da literatura feminista - seja nas ciências biológicas, seja nas ciências humanas e sociais - ou transformá-lo todo em gênero é um risco, que Haraway identifica como perder muito: primeiro porque a tensão sexo/gênero é produtiva, depois porque seria uma perda dentro do "poder analítico no interior de uma tradição ocidental específica" e, ainda - o principal ponto -, porque se perde-se o corpo como produtor e fica-se de novo apenas com corpo como "página em branco para inscrições sociais, inclusive aquelas do discurso biológico" e, assim, voltamos ao início, entregando o corpo à dominação de uma biologia colonizadora ocidental (HARAWAY, 1995, p. 35). Não precisamos produzir essa perda. Haraway sustenta que esse resgate do sexo para mostrar que ele é gênero serve a colocar o corpo de novo em uma lógica de apropriação, dominação e produção - aquela que comentei no primeiro item dessa discussão dos corpos, da mente que domina o corpo, da cultura que domina a natureza.

\footnotetext{
${ }^{4}$ Essa é uma afirmação com algum ranço de colonialidade, pressupondo que o gênero seja uma experiência
} culturalmente universal. 


\section{Considerações conclusivas}

O que quis neste espaço, então, não foi transformar sexo em gênero: o que pretendi foi mostrar que a noção dominante binária de sexo não diz tudo sobre os corpos e que esses corpos, vistos como atores e agentes de sua corporificação, não são "como uma tela, ou um terreno, ou um recurso, e, finalmente, nunca como um escravo do senhor que encerra a dialética apenas na sua agência e em sua autoridade de conhecimento 'objetivo'” (HARAWAY, 1995, p. 36) e, quando ouvimos seus pleitos de legitimidade, eles podem em seu agir transformar o campo científico inclusive o da biologia -; algo como fizeram e fazem as ações pessoais e políticas de travestis, transexuais e intersexuais. É preciso, então, corrigir o dito: apesar de só conhecermos os corpos por meio da linguagem, esses a excedem e precisamos ver esses corpos como atores e agentes, dotando-os de capacidade de mudar a linguagem.

Ao dizer que o corpo importa, ao tomar sexo como categoria problematizável e como linguagem que define os limites do humano, a intenção é provocar uma inversão: nosso centro não pode ser o externo, o olhar de fora, a mirada da colonialidade. O corpo não poder ser tomado como objeto que deve ser moldado à linguagem, a todo custo. Corpos falam e criam sua própria linguagem. Corpos existem em multiplicidade de formas. E se o sexo, assim como o gênero, faz parte dessa normatividade que define quem conta como humano, é fundamental que não o abandonemos em nossas pesquisas: o sexo importa - ou deve importar - quando pretendemos pensar fora da colonialidade.

\section{Referências}

AUSTIN, John L. How to do things with words. 2. ed. Harvard: Harvard University Press, 1975.

BEAUVOIR, Simone de. O segundo sexo. 2. ed. Tradução de Sérgio Milliet. Rio de Janeiro: Nova Fronteira, 2009.

BENTO, Berenice. A reinvenção do corpo: sexualidade e gênero na experiência transexual. Rio de Janeiro: Garamond, 2006.

BUTLER, Judith. Antigone's Claim: Kinship Between Life and Death. New York: Columbia University Press, 2000.

BUTLER, Judith. Bodies That Matter: On the Discursive Limits of "Sex". New York: Routledge, 1993.

BUTLER, Judith. Excitable Speech: a politics of the performative. New York: Routledge, 1997.

BUTLER, Judith. Problemas de gênero: feminismo e subversão da identidade. Tradução de Renato Aguiar. Rio de Janeiro: Civilização Brasileira, 2003.

BUTLER, Judith. "Sex and Gender in Simone de Beauvoir's Second Sex". Yale French Studies, n. 72, p. 35-49, Winter 1986. (Simone de Beauvoir: Witness to a Century)

BUTLER, Judith. Undoing Gender. New York: Routledge, 2004.

BUTLER, Judith. "Variations on Sex and Gender: Beauvoir, Wittig, and Foucault". In: BENHABIB, Seyla; CORNELL, Drucilla (Eds.). Feminism as Critique: Essays on the Politics of Gender in Late-Capitalist Societies. Feminist Perspectives. Cambridge/ Minneapolis: Polity Press/University of Minnesota Press, 1987.

CONNELL, Raewyn; PEARSE, Rebecca. Gênero: uma perspectiva global. Tradução de Marília Moschkovich. São Paulo: NVersos, 2015.

FAUSTO-STERLING, Anne. Sex/gender: biology in a social world. New York: Routledge, 2012.

FAUSTO-STERLING, Anne. Sexing the Body: Gender Politics and the Construction of Sexuality. New York: Basic Books, 2000.

FELMAN, Shoshana. The scandal of the speaking body: Don Juan with J. L. Austin, or seduction in two Languages. Tradução de Catherine Porter. Stanford: Stanford University Press, 2003.

GUIMARÃES JR., Anibal Ribeiro. Identidade cirúrgica: o melhor interesse da criança intersexo portadora de genitália ambígua. Uma perspectiva bioética. 2014. Tese (Doutorado) - Fundação Oswaldo Cruz, Escola Nacional de Saúde Pública Sérgio Arouca, Rio de Janeiro, RJ, Brasil. 
HARAWAY, Donna J. "Manifesto ciborgue: ciência, tecnologia e feminismo-socialista no final do século XX". In: TADEU, Tomaz et al. (Orgs.). Antropologia do ciborgue: as vertigens do pós-humano. Tradução de Tomaz Tadeu. 2. ed. Belo Horizonte: Autêntica, 2009. p. 33-118.

HARAWAY, Donna J. "Saberes localizados: a questão da ciência para o feminismo e o privilégio da perspectiva parcial”. Cadernos Pagu, Campinas, n. 5, p. 07-41, 1995.

KUNZRU, Hari. “'Você é um ciborgue': Um encontro com Donna Haraway”. In: TADEU, Tomaz et al. (Orgs.). Antropologia do ciborgue: as vertigens do pós-humano. Tradução de Tomaz Tadeu. 2. ed. Belo Horizonte: Autêntica, 2009. p. 17-32.

LAQUEUR, Thomas. Inventando o sexo: corpo e gênero dos gregos a Freud. Tradução de Vera Whately. Rio de Janeiro: Relume Dumará, 2001.

LUGONES, María. "Rumo a um feminismo decolonial". Revista Estudos Feministas, Florianópolis, v. 22, n. 3, p. 935-952, set.-dez. 2014. Disponível em https://periodicos.ufsc.br/index.php/ref/article/ view/36755. Acesso em 03/08/2020. ISSN 1806-9584.

MACHADO, Paula Sandrine. "Intersexualidade e o 'Consenso de Chicago': as vicissitudes da nomenclatura e suas implicações regulatórias". Revista Brasileira de Ciências Sociais, São Paulo, v. 23, n. $68,2008 b$.

MACHADO, Paula Sandrine. O Sexo dos Anjos: representações e práticas em torno do gerenciamento sociomédico e cotidiano da intersexualidade. 2008a. Tese (Doutorado) - Programa de PósGraduação em Antropologia Social, Instituto de Filosofia e Ciências Humanas, Universidade Federal do Rio Grande do Sul, Porto Alegre, RS, Brasil.

MAGALHÃES GOMES, Camilla de. "Os sujeitos do performativo jurídico: relendo a dignidade da pessoa humana nos marcos de gênero e raça". Revista Direito e Práxis, Rio de Janeiro, v. 10, n. 2, p. 871-905, 2019a. Disponível em https://www.e-publicacoes.uerj.br/index.php/revistaceaju/article/ view/30194. Acesso em 28/08/2019. ISSN: $2179-8966$.

MAGALHÃES GOMES, Camilla de. Temis Travesti: as relações genero, raça e direito para uma narrativa expansiva do "humano". Rio de Janeiro: Lumen Juris, 2019b.

PIRES, Barbara Gomes. "Intersexualidade: os caminhos médico-científicos e afetivos de um corpo ambíguo". In: 29a REUNIÃO BRASILEIRA DE ANTROPOLOGIA. Anais Eletrônicos... Natal, 2014. Disponível em http://www.29rba.abant.org.br/resources/anais/1/1401979672_ARQUIVO_Intersexualidade_29RBA BarbaraPires.pdf. Acesso em 15/01/2016.

PRECIADO, Beatriz. Texto Yonqui. Buenos Aires: Paidos, 2014.

Camilla de Magalhães Gomes (camillamaggo@gmail.com) é doutora em Direito, Estado e Constituição pela Universidade de Brasília (UnB, Brasiilia, DF, Brasil). Professora de Direito Penal e Processo Penal do UniCEUB. Coordenadora do projeto de extensão em violência doméstica/ PROVID no Centro Universitário de Brasília (UniCEUB) em Brasília, DF, Brasil. Professora associada ao Programa de Pós-Graduação Strictu Sensu em Direito do Centro Universitário de Brasília - UniCEUB.

\section{COMO CITAR ESSE ARTIGO DE ACORDO COM AS NORMAS DA REVISTA}

MAGALHÃES GOMES, Camilla de. "O corpo importa: corpos falantes e a produção discursiva do sexo". Revista Estudos Feministas, Florianópolis, v. 28, n. 3, e59271, 2020.

CONTRIBUIÇÃO DE AUTORIA

Não se aplica.

FINANCIAMENTO

Não se aplica.

CONSENTIMENTO DE USO DE IMAGEM

Não se aplica. 
APROVAÇÃO DE COMITÊ DE ÉTICA EM PESQUISA

Não se aplica.

CONFLITO DE INTERESSES

Não se aplica.

LICENÇA DE USO

Este artigo está licenciado sob a Licença Creative Commons CC-BY International. Com essa licença você pode compartilhar, adaptar, criar para qualquer fim, desde que atribua a autoria da obra.

\section{HISTÓRICO}

Recebido em 19/09/2018

Reapresentado em 28/01/2020

Reapresentado em 04/02/2020

Aprovado em 06/04/2020 